\title{
CRECIMIENTO DE HABA EN SIMBIOSIS CON MICROORGANISMOS NATIVOS DE REGIONES PRODUCTORAS DEL NORTE DE PUEBLA, MÉXICO
}

\section{GROWTH OF BROAD BEAN IN SYMBIOSIS WITH MICROORGANISMS NATIVE TO PRODUCTION REGIONS OF NORTHERN PUEBLA, MEXICO}

\author{
Citlalli Harris-Valle*, Ezequiel Mora-Guzmán, Martín Palafox-Rodríguez, \\ Cesar K. Pérez-Pacheco, Viridiana Mejía-Franco y Yadira Vázquez-Flores
}

Instituto Tecnológico Superior de Zacapoaxtla, Totoltepec, Zacapoaxtla, Puebla, México.

*Autor de correspondencia (citlalliharris@yahoo.com.mx)

\section{RESUMEN}

Vicia faba L. es una leguminosa que se produce principalmente en zonas frías, pero requiere fertilizantes y plaguicidas sintéticos para mantener la producción. Esta leguminosa se cultiva en la región nororiental de Puebla, México, donde es viable utilizar microorganismos simbiontes nativos como biofertilizantes para disminuir el uso de agroquímicos. El objetivo del estudio fue aislar y describir bacterias fijadoras de nitrógeno (BFN) y hongos micorrízicos arbusculares (HMA) a partir de cultivos de haba en los municipios de Libres, Zaragoza y Xochitlán de Vicente Suárez, Puebla, México para formular y evaluar biofertilizantes bajo cultivo protegido de haba; asimismo, se estudió el efecto del origen y de la inoculación individual o simultánea de BFN y HMA. Se realizaron tres ensayos BFN, HMA y BFN-HMA bajo un diseño experimental completamente al azar, cada uno con cuatro tratamientos (tres por el origen de la cepa y el testigo). Después de la floración se evaluó la biomasa seca y fresca, concentración de nitrógeno en hojas, colonización micorrízica y nodulación en las raíces de las plantas. Los microorganismos fueron similares entre las tres localidades; no obstante, el origen de las bacterias modificó su respuesta in vitro de acuerdo con el pH, temperatura y salinidad. El crecimiento de las plantas y la concentración de nitrógeno en las hojas no mostraron diferencias significativas entre los tratamientos con BFN o HMA, pero los valores se incrementaron $10 \%$ en ambas variables con BFN-HMA vs. testigo. No hubo diferencia significativa en la respuesta de las plantas en función del origen de BFN y HMA. Existe potencial para elaborar biofertilizantes que permitan disminuir el uso de agroquímicos en el cultivo de haba.

Palabras clave: Vicia faba, bacterias fijadoras, hongos micorrízicos arbusculares, biofertilizante.

\section{SUMMARY}

Vicia faba L. is a legume produced mainly in cold areas, but it requires fertilizers and synthetic pesticides to maintain production. This legume is grown in the Northeastern region of Puebla, Mexico, where it is feasible to use native symbiont microorganisms as biofertilizers to reduce the use of agrochemicals. The objective of this study was to isolate and describe nitrogen fixing bacteria (NFB) and arbuscular mycorrhizal fungi (AMF) from broad bean crops in the municipalities of Libres, Zaragoza and Xochitlán de Vicente Suárez, Puebla, Mexico to formulate and evaluate biofertilizers under protected cultivation of broad bean; likewise, the effect of the origin and that of the individual or simultaneous inoculation of NFB and AMF was studied. Three trials were conducted NFB, AMF and NFB-AMF under a completely randomized experimental design, each with four treatments (three for the origin of the strain and the control). After flowering, dry and fresh biomass nitrogen concentration in leaves, mycorrhizal colonization and nodulation in plant roots were evaluated. The microorganisms were similar among the three localities; however, the origin of the bacteria modified their response in vitro according to $\mathrm{pH}$, temperature and salinity. The growth of plants and concentration of nitrogen in the leaves showed no significant differences among treatments with NFB or AMF, but the values increased by $10 \%$ in both variables with NFB-AMF vs. control. There was no significant difference in the response of the plants in relation to the origin of NFB and AMF. There is potential to produce biofertilizers that allow reducing the use of agrochemicals in broad bean cultivation.

Index words: Vicia faba, fixing bacteria, arbuscular mycorrhizal fungi, biofertilizer.

\section{INTRODUCCIÓN}

En México el cultivo del haba (Vicia faba L.) tiene importancia económica y social porque es un alimento básico para los pobladores, principalmente en el centro del país, donde se cultiva regularmente en los estados de Tlaxcala y Puebla mediante prácticas tradicionales (RojasTiempo et al., 2012). La superficie nacional cultivada con haba en 2018 fue de 32,973 ha; de ella se obtuvieron 75,231 t de haba verde y 37,046 t de grano; Puebla es el mayor productor de haba para grano en México, donde se cultivaron 12,173 ha en 2018, con una produccción de 16,359 t, lo que representa 44 \% de la producción nacional (SIAP, 2019).

Algunos trabajos sugieren que la fertilización fosfórica incrementa el rendimiento de grano de haba y en manuales agrícolas se sugiere una fertilización química de 200 kg ha $^{-1}$ de 16N-46P-00K (Morales et al., 2002; Peralta et al., 2013). No obstante, se considera importante encontrar alternativas para cambiar el uso de agroquímicos por biofertilizantes a base de hongos y bacterias simbiontes, ya que la asociación de estos microorganismos no solamente incrementa la producción de flores y frutos, también mejora la calidad de los suelos (Gianinazzi et al., 
2010; Smith y Read, 2008; Workalemahu, 2009).

En leguminosas la inoculación artificial de hongos micorrízicos arbusculares (HMA) y bacterias fijadoras de nitrógeno (BFN) mejora el estado nutricional de las plantas y disminuye el daño causado por diferentes tipos de estrés abiótico (Aroca et al., 2007; Rabie y Almadini, 2005). Se ha descrito un efecto sinérgico en la simbiosis de BFN y HMA que incrementa la asimilación de $\mathrm{N}$ y $\mathrm{P}$ en mayor medida que cuando se utiliza solamente un tipo de microorganismo (Xavier y Germida, 2002; 2003). En épocas más recientes se ha puesto especial interés en caracterizar microorganismos nativos por considerarse más efectivos como inoculantes que los organismos no nativos bajo condiciones ambientales estresantes (Bothe et al., 2010).

En cuanto al origen de los organismos utilizados como biofertilizantes, existen datos que ponen de manifiesto la importancia de la identidad de los simbiontes para incrementar la eficiencia de la asociación y los beneficios para la planta; por ejemplo, la luz (Villegas-Olivera et al., 2017) y las bajas temperaturas originan cambios en la colonización de las diferentes especies de HMA (Latef y Chaoxing, 2011; Zhu et al., 2010). Los cambios en las comunidades de HMA se explican por la fluctuación en la temperatura ambiental, lo cual impacta en el desarrollo de los hongos y de la planta hospedera (Fitter et al., 2000). Gavito y Azcón-Aguilar (2012) encontraron que organismos procedentes de zonas frías toleran mejor las bajas temperaturas que los de zonas templadas, ya que presentan variaciones genéticas y plasticidad, lo que les permite adaptarse a esas condiciones ambientales extremas. En habas cultivadas en suelos alcalinos, la coinoculación de BFN y HMA incrementa el crecimiento de la planta medido como biomasa seca total (Abd-Alla et al., 2014). En frijol (Phaseolus vulgaris L.), la asociación plantahongo-Rhizobium incrementa la fijación de nitrógeno y la eficiencia en el uso del P (Tajini et al., 2012).

El objetivo del estudio fue caracterizar hongos micorrízicos arbusculares y bacterias fijadoras de nitrógeno nativas de tres regiones productoras de haba en el nororiente de Puebla y evaluar su efecto en el crecimiento y fijación de nitrógeno en $V$. faba cultivada en invernadero, tras inocular BFN, HMA y BFN-HMA. Las premisas son que existen diferencias en la respuesta de las plantas a la inoculación de simbiontes en función del origen de las cepas, teniendo mayor crecimiento con aquellos que proceden de las zonas con clima similar al sitio de cultivo; asimismo, se espera que BFN-HMA incremente la biomasa seca y fresca, y nitrógeno total en hojas en comparación con BFN, HMA o el testigo.

\section{MATERIALES Y MÉTODOS}

\section{Muestreo de suelo y aislamiento de microorganismos}

Se obtuvieron aleatoriamente muestras de suelo y raíz de la región productora de haba de los municipios de Libres, Zaragoza y Xochitlán de Vicente Suárez, Puebla a partir de cuadrantes de $1 \mathrm{~m}^{2}$. Una muestra compuesta por cuadrante consistió en la mezcla de aproximadamente $10 \mathrm{~cm}^{3}$ de suelo extraído a $5-10 \mathrm{~cm}$ del tallo y $20 \mathrm{~cm}$ de profundidad de todas las plantas del cuadrante. Se obtuvieron un total de tres muestras por localidad de un solo campo de cultivo. En el laboratorio, las muestras se refrigeraron a $4{ }^{\circ} \mathrm{C}$ hasta su análisis y las raíces se lavaron y colocaron en etanol $70 \%$ por un periodo no mayor a $5 \mathrm{~d}$.

Para el aislamiento de las BFN se seleccionaron entre cinco y 10 nódulos de las raíces de 3 a $5 \mathrm{~mm}$ de diámetro. Los nódulos se lavaron con agua destilada y se colocaron en una solución de ácido clorhídrico 2 \% y se agitaron con vórtex por $1 \mathrm{~min}$; finalmente, se enjuagaron con agua destilada estéril y se lavaron con etanol $95 \%$ durante 4 min. Los nódulos se molieron con mortero hasta lograr una mezcla homogénea, la cual se colocó en tubos de ensayo con medio de extracto de levadura-manitol. A partir de los cultivos líquidos se tomó una muestra con asa bacteriológica y se sembró por estriado en un medio de extracto de levadura manitol agar-Rojo Congo (ELMA-RC) por el método de estriado y se cultivaron a $28^{\circ} \mathrm{C}$ durante 5 d. A partir de los cultivos en sólido se realizaron resiembras sucesivas hasta lograr el aislamiento.

\section{Identificación y caracterización de bacterias}

Las BFN se identificaron morfológicamente de acuerdo con Somasegaran y Hoben (1994). Las pruebas bioquímicas basadas en los procedimientos de MacFaddin (2000) incluyeron evaluaciones de movilidad-indolornitina con el medio MIO (peptona de carne y caseína, extracto de levadura, L-ornitina, dextrosa, púrpura de bromocresol y agar); se evaluó la utilización de azúcares con el medio TAH (triple azúcar-hierro, lactosa, sacarosa y glucosa), urea con agar urea (agar base urea) y citratos con medio agar citrato de Simmons (fosfato dibásico de amonio, sulfato de magnesio, fosfato dipotásico, azul de bromotimol, cloruro de sodio, citrato de sodio y agar). Las pruebas de descarboxilación de aminoácidos se hicieron por la inducción de enzimas específicas mediante el medio $\mathrm{AHL}$ (agar de hierro y lisina) que produce una respuesta colorimétrica.

La caracterización de las bacterias se hizo con evaluación del crecimiento in vitro a diferentes temperaturas $(4,20,35$ 
y $\left.45^{\circ} \mathrm{C}\right), \mathrm{pH}(5,6,7$ y 8$)$ y salinidad $(0.25,0.5,0.75$ y $1 \%$ de $\mathrm{NaCl}$ ) en medio líquido LM (levadura-manitol) con base en lo descrito por Hernández et al. (2012). Las bacterias se inocularon en el medio líquido con una asada a partir de las colonias previamente aisladas. Los cultivos se mantuvieron en agitación constante con control de temperatura, a una velocidad de $70 \mathrm{rpm}$ durante una semana. El monitoreo se realizó cada 12 h mediante espectrofotometría (540 nm); los resultados se compararon con una curva de calibración absorbancia vs. número de células para obtener el tiempo generacional y calcular el número de generaciones con base en la fórmula de Lambert-Beer, de acuerdo con Harris (2007).

\section{Inoculación bacteriana}

El inóculo de bacterias se preparó cultivando las cepas previamente aisladas en medio líquido ELM-RC en agitación a $20^{\circ} \mathrm{C}$. La concentración en el inóculo se ajustó a $10^{9}$ células $\mathrm{mL}^{-1}$ (Somasegaran y Hoben, 1994). Para la inoculación se aplicó $1 \mathrm{~mL}$ del cultivo bacteriano a cada maceta con los cultivos de haba en una sola ocasión y a los 30 d después de la germinación, según lo propuesto por Workalemahu (2009).

\section{Preparación de hongos micorrízicos e inoculación}

Para la producción de inóculo de HMA se utilizó sorgo (Sorghum spp.) como planta trampa. El cultivo se hizo en un sustrato inerte de vermiculita; después de tres semanas de germinación se inocularon las plantas con suelo procedente de campo. Para la inoculación las muestras de suelo se tamizaron en húmedo con mallas de 60, 120 y 250 um, se cuantificó el número de esporas en los tamices de 60 y $120 \mu \mathrm{m}$ mediante un diferencial de sacarosa y la observación en microscopio estereoscópico para inocular cerca de 100 esporas por planta en los cultivos de sorgo. En el monitoreo del desarrollo de los HMA en las plantas trampa se observó la colonización de raíces mediante la tinción con azul de Tripano $5 \%$, se verificó el establecimiento de la simbiosis. Cuando las plantas iniciaron la formación de espigas se identificaron las morfoespecies y la cantidad total de esporas. Se consideró un inóculo listo cuando se contabilizaron aproximadamente 100 esporas g $^{-1}$ de suelo (Liu y Wang, 2003). Se hicieron cultivos independientes para cada localidad con tres repeticiones y un testigo, sin inoculación de suelo.

Los experimentos con plantas se realizaron en condiciones controladas de invernadero en Zacapoaxtla, Puebla. Se inició con la germinación de semillas (dos por maceta) de haba desinfectadas en macetas de $4 \mathrm{~kg}$ con una mezcla de arena:tierra:humus $(1: 2: 1 \mathrm{v} / \mathrm{v} / \mathrm{v})$, previamente tratada con doble esterilización $\left(120{ }^{\circ} \mathrm{C}\right.$ y $1.40-1.75 \mathrm{~kg}$ $\mathrm{cm}^{-2}$ ). Para la inoculación con los simbiontes probados de manera independiente, los hongos o las bacterias se agregaron 30 d después de la germinación, mientras que en HMA-BFN las bacterias y hongos se añadieron a los 30 y $37 \mathrm{~d}$, respectivamente. Para los ensayos de respuesta del haba a la simbiosis se utilizaron tres experimentos independientes BFN, HMA y BFN-HMA. En cada experimento hubo cuatro tratamientos, uno para cada cepa de las tres localidades (Libres, Zaragoza y Xochitlán) y el testigo. Los cultivos se mantuvieron en invernadero con iluminación natural y temperatura ambiente durante diciembre a marzo, periodo regular de siembra en la región. Las plantas se regaron semanalmente con $100 \mathrm{~mL}$ de agua filtrada.

\section{Variables respuesta}

Después de la floración las plantas se extrajeron para separar la raíz del vástago; se cuantificó el peso fresco de cada parte y se colocó en una estufa a $45^{\circ} \mathrm{C}$ durante 48 h hasta peso constante y se determinó el peso seco. La concentración de nitrógeno se midió por el método de Kjeldahl (1883). El nivel de simbiosis (número de nódulos por raíz) se cuantificó categorizando la nodulación en las raíces de acuerdo con Amijee y Giller (1998). Para conocer el nivel de colonización micorrízica se tiñeron de 100 a 150 mg de raíces secas $\left(45^{\circ} \mathrm{C}\right)$ con azul de Tripano, después de aclarar los tejidos con $\mathrm{KOH} 10 \%$, según lo descrito por Phillips y Hayman (1970). El porcentaje de colonización se calculó con el número de segmentos de raíz con micelio intracelular con respecto al número total de raíces (Biermann y Linderman, 1983).

\section{Diseño experimental y análisis estadístico}

El diseño experimental de los tres experimentos independientes (BFN, HMAyBFN-HMA) fuecompletamente aleatorizado con cuatro repeticiones, para un total de 16 unidades experimentales, consistentes en una maceta con una planta. Los datos se analizaron mediante análisis de varianza, previa verificación de normalidad en los datos y la comparación de medias se hizo por el método de TukeyKramer, con una probabilidad $\mathrm{P} \leq 0.05$.

\section{RESULTADOS Y DISCUSIÓN}

\section{Cracterización de los simbiontes}

Se detectaron dos morfoespecies de HMA (Figura 1), identificadas como A y B según el orden en que se encontraron. Las primeras se observaron únicamente en las plantas inoculadas con suelos procedentes de Zaragoza (Figura 1A), mientras que el tipo B se detectó 
en los tres sitios (Figura 1B). Se observaron diferencias en el grosor de la pared esporal, ornamentación (tipo A) y presencia de cicatriz de unión a hifa de sostén (tipo B). La cuantificación total de esporas en el sustrato de las plantas trampa fue de aproximadamente 100 esporas $\mathrm{g}^{-1}$ de suelo, dentro de lo recomendado por Liu y Wang (2003). Las características bioquímicas de Rhizobium, aislada a partir de raíces de plantas de cada uno de los sitios seleccionados se muestran en el Cuadro 1. La información sugiere que se trata de una misma especie.

\section{Respuesta de las cepas a factores ambientales}

En la Figura 2 se presenta la respuesta de las distintas cepas ante los factores ambientales temperatura, $\mathrm{pH}$ y salinidad sobre el crecimiento bacteriano. Los datos indican que, dependiendo del clima predominante en sitios de origen, el crecimiento de las bacterias es diferentes en los distintos niveles de los tres factores evaluados. Existen diferencias climáticas contrastantes entre los municipios estudiados: clima frío-seco (Libres), húmedofrío (Zaragoza) y húmedo-cálido (Xochitlán).

En cuanto a temperatura, el mayor crecimiento de las tres cepas fue a $20^{\circ} \mathrm{C}$; aunque los valores óptimos de Rhizobium son alrededor de $20{ }^{\circ} \mathrm{C}$, existen cepas con tolerancia a temperatura, que permiten una tasa de reproducción relativamente constante en amplios intervalos (Ogata y Zúñiga, 2008). La cepa de Zaragoza creció significativamente más a $4{ }^{\circ} \mathrm{C}$, la cepa de Libres a 35 ${ }^{\circ} \mathrm{C}$ y la cepa de Xochitlán a $45^{\circ} \mathrm{C}$, mientas que la de Libres se inhibió completamente con esta última temperatura. En general, Rhizobium presenta crecimiento lento a pH ácido (Hernández et al., 2012). En este estudio, las cepas de Libres y Xochitlán crecieron mejor a pH 7, mientras que la de Zaragoza lo hizo a pH 8. La cepa de Libres es más susceptible a pH bajo y la de Xochitlán a pH alto.
En cuanto a la salinidad, la cepa de Libres creció mejor a $0.25 \%$ de NaCl, el aislado de Xochitlán se desarrolló igual en todos los niveles de salinidad evaluados y la cepa de Zaragoza fue resistente al $1 \%$ de $\mathrm{NaCl}$, con un crecimiento similar al observado en la salinidad más baja. Cuadrado et al. (2009) señalaron que algunas cepas de Rhizobium son capaces de tolerar una salinidad de hasta $5.5 \%$ de $\mathrm{NaCl}$, aunque su crecimiento es lento. Estos autores sugieren que las cepas con mayor tolerancia a condiciones extremas son candidatas idóneas para utilizarse como bioinoculantes.

En el experimento combinado de bacterias y hongos (BFN-HMA) se observaron diferencias estadísticas en todas las variables morfométricas. El peso fresco en plantas con BFM-HMA presentó valores mayores que el testigo (más de $10 \mathrm{~g}$ de diferencia), mientras que solamente el peso seco del tejido aéreo fue menor en el testigo en comparación con el resto de tratamientos con HMA de las tres zonas, con una diferencia de 1 a $2 \mathrm{~g}$. Con BFN se observó que el peso fresco del vástago con la cepa de Xochitlán fue de $5 \mathrm{~g}$ más que con las otras cepas y el testigo. Con HMA todas las variables morfométricas fueron estadísticamente similares en los tratamientos (Cuadro 2). Lo anterior puede relacionarse con el balance costo-beneficio de la asociación, pues se considera benéfico cuando la planta transfiere carbono al huésped y éste retribuye facilitando la tasa de fijación de carbono por unidad de área, lo que mejora la asimilación de nutrientes y disminuye los requerimientos para producir o mantener una unidad de área fotosintética. Lo contrario puede presentarse, y entonces, la interacción pasa de simbiosis a parasitismo, cuando la retribución del hospedero no compensa el gasto de la transferencia de $C$ al huésped (Lapointe y Molard, 1997; Tinker et al., 1994; Wright et al., 1998).
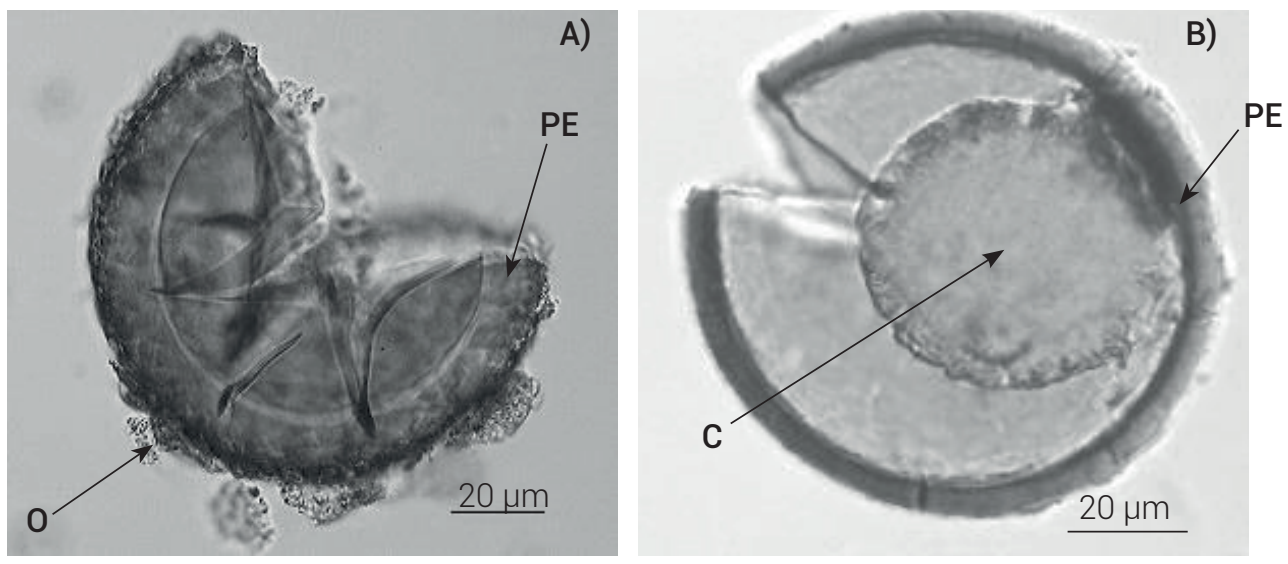

Figura 1. Esporas de HMA encontradas en plantas trampa con suelo de Zaragoza (A) y en los tres sitios muestreados (B). Pared de la espora (PE), cicatriz de unión a la hifa de sostén (C) y ornamentación (0). 
Cuadro 1. Caracterización bioquímica de las cepas de Rhizobium sp. aisladas de tres campos de cultivo de haba en Puebla.

\begin{tabular}{lcccc}
\hline \multirow{2}{*}{ Medio } & Variable & & Localidad & \\
\cline { 2 - 4 } Motilidad-indol-ornitina & Movilidad & Libres & Zaragoza & Xochitlán \\
& Indol & - & - & - \\
& Ornitina & - & - & - \\
Agar-lisina-hierro & Descarboxilación Lisina & - & - & - \\
\cline { 2 - 4 } & Desaminación Lisina & + & - & - \\
Motilidad-sulfuro-indol & $\mathrm{H}_{2} \mathrm{~S}$ & - & + & + \\
\cline { 2 - 4 } & Glucosa & + & - & + \\
& Lactosa & + & + & + \\
& Sacarosa & + & + & - \\
& Urea & - & - & - \\
\hline
\end{tabular}

+: reacción positiva, -: reacción negativa.
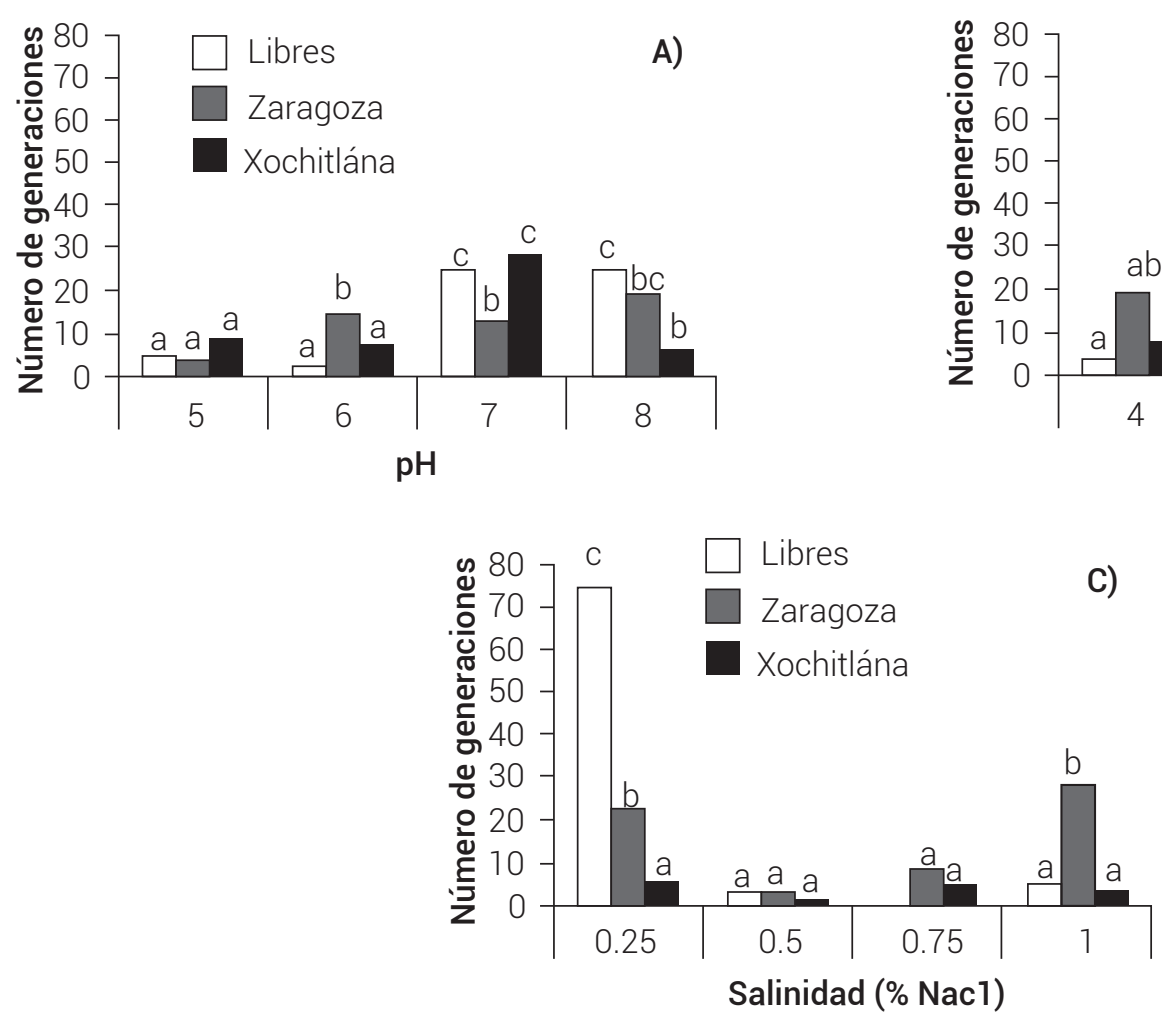

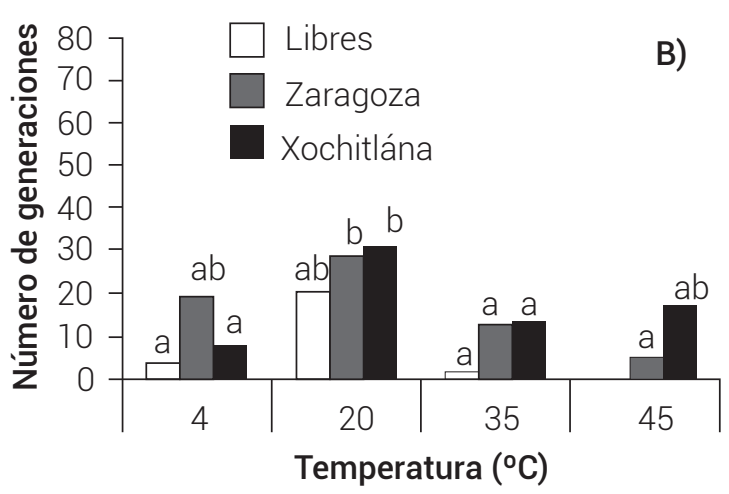

C)
B)

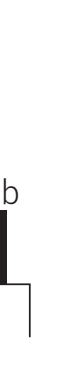


Cuadro 2. Crecimiento de las plantas inoculadas con bacterias fijadoras de nitrógeno (BFN), hongos micorrízicos arbusculares (HMA) y BFN-HMA.

\begin{tabular}{|c|c|c|c|c|c|c|c|c|c|}
\hline \multirow{2}{*}{ Inoculante } & \multirow{2}{*}{ Origen } & \multicolumn{2}{|c|}{$\mathrm{PF}(\mathrm{g})$} & \multicolumn{2}{|c|}{ PS (g) } & \multicolumn{2}{|c|}{ Total (g) } & \multirow{2}{*}[\mathrm{N}]{$(\%)$} & \multirow{2}{*}{$\begin{array}{c}\text { CM/CN } \\
\text { (\%/categoría) }\end{array}$} \\
\hline & & Aéreo & Raíz & Aéreo & Raíz & PF & PS & & \\
\hline \multirow{4}{*}{ HMA } & Libres & 28.9 & 36.8 & 15.5 & 18.2 & 65.7 & 33.7 & $0.31 \mathrm{a}$ & 95 a /NA \\
\hline & Xochitlán & 30.1 & 31.9 & 11.4 & 20.5 & 62 & 31.9 & $0.30 \mathrm{a}$ & 97 a /NA \\
\hline & Zaragoza & 29.3 & 29.0 & 15.3 & 20.0 & 58.3 & 35.3 & $0.31 \mathrm{a}$ & 98 a /NA \\
\hline & Testigo & 26.2 & 37.4 & 18.4 & 22.2 & 63.6 & 40.7 & $0.23 b$ & $62 \mathrm{~b} / \mathrm{NA}$ \\
\hline \multirow{4}{*}{ BFN } & Libres & $23.5 b$ & 32.6 & 4.5 & 2.2 & $56.1 \mathrm{~b}$ & 6.7 & $2.46 \mathrm{a}$ & NA/ Baja \\
\hline & Xochitlán & $31.2 \mathrm{a}$ & 31.2 & 5.0 & 2.0 & $62.4 \mathrm{a}$ & 6.9 & $1.96 \mathrm{~b}$ & NA/ Media \\
\hline & Zaragoza & $25.8 \mathrm{~b}$ & 31.9 & 4.7 & 2.7 & $57.7 \mathrm{~b}$ & 7.4 & $2.69 a$ & NA/ Media \\
\hline & Testigo & $4.8 \mathrm{~b}$ & 31.2 & 4.0 & 2.4 & $56.0 \mathrm{~b}$ & 6.4 & $2.21 \mathrm{~b}$ & NA/ Baja \\
\hline \multirow{4}{*}{ HMA-BFN } & Libres & 79.6 a & 133.7 a & $7.0 \mathrm{a}$ & $13.8 \mathrm{~b}$ & $213 a$ & $20.8 b$ & $0.33 a$ & 100 a /Media \\
\hline & Xochitlán & $83.6 \mathrm{a}$ & $133.5 \mathrm{a}$ & $5.8 \mathrm{a}$ & $26.8 \mathrm{a}$ & $217 a$ & $32.6 \mathrm{a}$ & $0.36 \mathrm{a}$ & 100 a /Media \\
\hline & Zaragoza & $82.1 \mathrm{a}$ & $128.5 \mathrm{a}$ & $6.2 \mathrm{a}$ & $11.5 b$ & $211 a$ & $17.8 \mathrm{~b}$ & $0.39 a$ & 100 a /Media \\
\hline & Testigo & $72.9 \mathrm{~b}$ & 105.7 b & $4.8 \mathrm{~b}$ & $16.1 \mathrm{~b}$ & 179 & $21.0 \mathrm{~b}$ & $0.25 b$ & 70 b /Baja \\
\hline
\end{tabular}

Medias con letras iguales no son estadísticamente diferentes (Tukey-Kramer, 0.05). PF: peso fresco, PS: peso seco, [N]: concentración de nitrógeno, CM/CN: colonización micorrízica/categoría de nodulación, NA: no aplica.

Con la inoculación de HMA se obtuvieron valores más altos de concentración de nitrógeno en las plantas con respecto a las no inoculadas. Aunque se considera que Ios HMA facilitan principalmente la asimilación de P, está documentado que también mejoran la asimilación de otros nutrientes como N. Vitis vinifera $\mathrm{L}$. en simbiosis con Glomus fasciculatum presentó altos niveles de nitrógeno (Alarcón et al., 2001). En las plantas testigo se encontró 30 \% menos colonización micorrízica en comparación con las habas inoculadas, donde fue superior al $90 \%$ y el peso fresco significativamente más alto que en el testigo. Se considera que la alta colonización micorrízica es inversa al desarrollo de la raíz. Aguirre y Kohashi-Shibata (2002) observaron más del $70 \%$ de colonización, pero un menor volumen y peso de la raíz en relación con el testigo en plantas de frijol. En este caso, se registró que el peso fresco de la raíz fue mayor por más de $20 \mathrm{~g}$ que en el testigo solamente cuando la inoculación fue con BFN-HMA.

En los tratamientos donde se inocularon BFN y BFNHMA se observó incremento en el peso de las plantas y en esos tratamientos se obtuvo un nivel de nodulación medio en las raíces. Ramírez-Elías et al. (2014) concluyeron que la única manera de obtener una respuesta positiva en el desarrollo y rendimiento vegetal con la inoculación de BFN es que la población bacteriana alcance una biomasa alta en la raíz; por lo tanto, para elaborar un inóculo de BFN debe considerarse su alta capacidad de colonización radicular.
Cuando se inocularon bacterias y hongos simbiontes se registraron incrementos significativos con respecto al testigo en todas las variables, excepto en el peso seco de la raíz. Para esta última variable, los valores más altos se obtuvieron con la cepa de Zaragoza (más de $10 \mathrm{~g}$ de diferencia en comparación con los demás tratamientos). El peso fresco de la raíz se incrementó en más de $20 \mathrm{~g}$, el fresco aéreo en más de $5 \mathrm{~g}$, y el contenido de nitrógeno en alrededor de $0.1 \%$. En las plantas con BFN-HMA la colonización de las raíces fue 100 \% y la nodulación media en comparación con $70 \%$ de colonización micorrízica y nodulación baja en el testigo. En kudzú (Pueraria phaseoloides) se encontró que la coinoculación con cepas de Rhizobium y Glomus producen incrementos de biomasa y de semillas (González et al., 2012).

En este estudio la inoculación simultánea de BFN-HMA mejoró las variables evaluadas en las plantas de haba en comparación con los microorganismos benéficos por separado, similar a lo encontrado en lenteja (Lens culinaris) por Xavier y Germida (2003). No se observó una relación entre el efecto benéfico y el sitio de origen de los microorganismos simbióticos. La inoculación individual de BFN o HMA únicamente incrementó la concentración de nitrógeno. Al parecer la presencia simultánea de BFN y HMA hace más evidente el crecimiento de la planta, similar a lo registrado en frijol por Jia et al. (2004), quienes lo atribuyeron a que uno de los microorganismos modifica la colonización de la raíz para el otro, lo que repercute positivamente en las variables morfométricas y fotosintéticas. 


\section{CONCLUSIONES}

Existe similitud entre los microorganismos simbióticos en los campos de cultivo de Vicia faba de Libres, Zaragoza y Xochitlán de Vicente Suárez, Puebla. En las tres localidades se encontraron esporas de hongos con la misma morfología y bacterias con características bioquímicas iguales. La concentración de nitrógeno fue mayor cuando se inocularon bacterias fijadoras de nitrógeno $u$ hongos micorrízicos arbusculares y cuando se inocularon ambos incrementó significativamente la biomasa. Los resultados sugieren que la respuesta no está relacionada con el origen geográfico de las cepas.

\section{AGRADECIMIENTOS}

Al C. Sadot Mora Ortigoza por su apoyo y colaboración durante todo el desarrollo del trabajo experimental. Al Tecnológico Nacional de México por el financiamiento del proyecto clave 355.15-PD.

\section{BIBLIOGRAFÍA}

Abd-Alla M. H., A. W. E. El-Enany, N. A. Nafady, D. M. Khalaf and F. M. Morsy (2014) Synergistic interaction of Rhizobium leguminosarum bv. viciae and arbuscular mycorrhizal fungi as a plant growth promoting biofertilizers for faba bean (Vicia faba L.) in alkaline soil. Microbiological Research 169:49-58, https://doi.org/10.1016/j.micres.2013.07.007

Aguirre M. J. F. y J. Kohashi-Shibata (2002) Dinámica de la colonización micorrízica y su efecto sobre los componentes del rendimiento y contenido de fósforo en frijol común. Agricultura Técnica en México 28:23-33.

Alarcón A., M. C. González-Chávez, R. Ferrera-Cerrato y A. VillegasMonter (2001) Efectividad de Glomus fasciculatum y Glomus etunicatum en el crecimiento de plántulas de Vitis vinifera L. obtenidas por micropropagación. Terra Latinoamericana 19:29-35.

Amijee F. and K. E. Giller (1998) Environmental constraints to nodulation and nitrogen fixation of Phaseolus vulgaris L. in Tanzania. I. A survey of soil fertility, root nodulation and multi-locational responses to rhizobium inoculation. African Crop Science Journal 6:159-170, https://doi.org/10.4314/acsj.v6i2.27812

Aroca R., R. Porcel and J. M. RuizLozano (2007) How does arbuscular mycorrhizal symbiosis regulate root hydraulic properties and plasma membrane aquaporins in Phaseolus vulgaris under drought, cold or salinity stresses? New Phytologist 173:808816, https://doi.org/10.1111/j.1469-8137.2006.01961.x

Biermann B. and R. G. Linderman (1983) Use of vesicular-arbuscular mycorrhizal roots, intraradical vesicles and extraradical vesicles as inoculum. New Phytologist 95:97-105, https://doi. org/10.1111/j.1469-8137.1983.tb03472.x

Bothe H., K. Turnau and M. Regvar (2010) The potential role of arbuscular mycorrhizal fungi in protecting endangered plants and habitats. Mycorrhiza 20:445457, https://doi.org/10.1007/s00572-010-0332-4

Cuadrado B., G. Rubio y W. Santos (2009) Caracterización de cepas de Rhizobium y Bradyrhizobium (con habilidad de nodulación) seleccionados de los cultivos de fríjol caupi (Vigna unguiculata) como potenciales bioinóculos. Revista Colombiana de Ciencias Químico Farmacéuticas 38:78-104.

Fitter A. H., A. Heinemeyer and P. L. Staddon (2000) The impact of elevated $\mathrm{CO}_{2}$ and global climate change on arbuscular mychorrizas: a mycocentric approach. New Phytologist 147:179-187, https://doi.org/10.1046/j.1469-8137.2000.00680.x
Gavito M. E. and C. Azcón-Aguilar (2012) Temperature stress in arbuscular mycorrhizal fungi: a test for adaptation to soil temperature in three isolates of Funneliformis mosseae from different climates. Agricultural and Food Science 21:2-11, https://doi org/10.23986/afsci.4994

Gianinazzi S., A. Gollotte, M. N. Binet, D. van Tuinen, D. Redecker and D. Wipf (2010) Agroecology: the key role of arbuscular mycorrhizas in ecosystem services. Mycorrhiza 20:519530, https://doi.org/10.1007/s00572-010-0333-3

González P. J., G. Pérez, N. Medina, G. Crespo, J. F. Ramírez y J. Arzola (2012) Coinoculación de cepas de rizobios y una cepa de hongo micorrízico arbuscular (Glomus cubense) y su efecto en kudzú (Pueraria phaseoloides). Revista Cubana de Ciencia Agrícola 46:331-334.

Harris D. C. (2007) Análisis Químico Cuantitativo. Editorial Reverté S.A Barcelona, España. 744 p.

Hernández J. L., J. G. Cubillos-Hinojosa y P. E. Milian (2012) Aislamiento de cepas de Rhizobium spp. asociados a dos leguminosas forrajeras en el Centro Biotecnológico del Caribe. Revista Colombiana de Microbiología Tropical 2:51-62.

Jia Y., V. M. Gray and C. J. Straker (2004) The influence of Rhizobium and arbuscular mycorrhizal fungi on nitrogen and phosphorus accumulation by Vicia faba. Annals of Botany 94:251-258, https://doi.org/10.1093/aob/mch135

Kjeldahl J. (1883) Neue methode zur bestimmung des stickstoffs in organischen körpern. Zeitschrift für Analytische Chemie 22:366-382, https://doi.org/10.1007/BF01338151

Lapointe L. and J. Molard (1997) Costs and benefits of mycorrhizal infection in a spring ephemeral Erythronium americanum. New Phytologist 135:491 500, https://doi.org/10.1046/j.1469-8137.1997.00672.x

Latef A. A. H. A. and H. Chaoxing (2011) Arbuscular mycorrhizal influence on growth, photosynthetic pigments, osmotic adjustment and oxidative stress in tomato plants subjected to low temperature stress. Acta Physiologiae Plantarum 33:1217-1225, https://doi.org/10.1007/s11738-010-0650-3

Liu R. and F. Wang (2003) Selection of appropriate host plants used in trap culture of arbuscular mycorrhizal fungi. Mycorrhiza 13:123-127, https://doi.org/10.1007/s00572-002-0207-4

MacFaddin J. F. (2000) Biochemical Tests for Identification of Medical Bacteria. 3rd edition. Lippincott Williams and Wilkins Philadelphia, USA. 928 p.

Morales R. E. J., H. De la 0 Á., A. Morales R. and V. M. de la Cruz A. (2002) Evaluación de cinco genotipos de haba (Vicia faba L.) con seis niveles de fósforo en Tecámac, México. Ciencia Ergo Sum 9:184-189

Ogata K. y D. Zúñiga (2008) Estudio de la microflora de la rizósfera de Caesalpinia spinosa en la provincia de Huanuco. Zonas Áridas 12:191-208.

Peralta I. E., A. Murillo I., N. Mazón 0., J. Pinzón Z. y E. Villacrés P. (2013) Manual agrícola de fréjol y otras leguminosas. Cultivo, variedades y costos de producción. Publicación Miscelánea 135. $3^{a}$ edición. Estación Experimental Santa Catalina, INIAP. Quito, Ecuador. 70 p.

Phillips J. M. and D. S. Hayman (1970) Improved procedures for clearing roots and staining parasitic and vesicular-arbuscular mycorrhizal fungi for rapid assessment of infection Transactions of the British Mycological Society 55:158-161, https://doi.org/10.1016/S0007-1536(70)80110-3

Rabie G. H. and A. M. Almadini (2005) Role of bioinoculants in development of salt-tolerance of Vicia faba plants under salinity stress. African Journal of Biotechnology 4:210-222.

Ramírez-Elías M. A., R. Ferrera-Cerrato, A. Alarcón, J. J. Almaráz, G. RamírezValverde, L. E. de-Bashan, F. J. Esparza-García and O. García-Barradas (2014) Identification of culturable microbial functional groups isolated from the rhizosphere of four species of mangroves and their biotechnological potential. Applied Soil Ecology 82:1-10, https://doi.org/10.1016/j.apsoil.2014.05.001

Rojas-Tiempo J., R. Díaz-Ruiz, F. Álvarez-Gaxiola, J. Ocampo-Mendoza y A. Escalante-Estrada (2012) Tecnología de producción de haba y características socioeconómicas de productores en Puebla y Tlaxcala. Revista Mexicana de Ciencias Agrícolas 3:35-49. 
SIAP, Servicio de Información Agroalimentaria y Pesquera (2019) Anuario estadístico de la producción agrícola. Servicio de Información Agroalimentaria y Pesquera, Secretaría de Agricultura y Desarrollo Rural. Ciudad de México. https://nube.siap.gob.mx/ cierreagricola/ (Septiembre 2019).

Smith S. E. and D. J. Read (2008) Mycorrhizal Symbiosis. $3^{\text {rd }}$ edition. Academic Press. London, UK. 800 p.

Somasegaran P. and H. J. Hoben (1994) Handbook for Rhizobia. Methods in Legume-Rhizobium Technology. Springer-Verlang. New York, USA. $450 \mathrm{p}$

Tajini F., M. Trabelsi and J. J. Drevon (2012) Arbuscular mycorrhizas by contact with mycorrhized Stylosanthes guianensis enhance P use efficiency for $\mathrm{N}_{2}$ fixation in the common bean (Phaseolus vulgaris L.). African Journal of Microbiology Research 6:12971305, https://doi.org/10.5897/AJMR11.1577

Tinker P. B., D. M. Durall and M. D. Jones (1994) Carbon use efficiency in mycorrhizas: theory and sample calculation. New Phytologist 128:115-122, https://doi.org/10.1111/j.1469-8137.1994.tb03994.x

Villegas-Olivera J.-A., J. Pérez-Moreno, G. Mata, J.-J. Almaraz-Suárez, E. Ojeda-Trejo and V. Espinosa-Hernández (2017) Type of light and formation of basidiomata of two species of edible ectomycorrhizal mushrooms associated with neo-tropical pines and the description of basidiomata development. Revista
Fitotecnia Mexicana 40:405-413

Wright D. P., D. J. Read and J. D. Scholes (1998) Mycorrhizal sink strength influences whole plant carbon balance of Trifolium repens L. Plant, Cell and Environment 21:881891, https://doi.org/10.1046/j.1365-3040.1998.00351.x

Workalemahu A. (2009) The effect of indigenous root-nodulating bacteria on nodulation and growth of faba bean (Vicia faba) in the low-input agricultural systems of Tigray Highlands, Northern Ethiopia. Momona Ethiopian Journal of Science 1:3043, https://doi.org/10.4314/mejs.v1i2.46047

Xavier L. J. C. and J. J. Germida (2002) Response of lentil under controlled conditions to co-inoculation with arbuscular mycorrhizal fungi and rhizobia varying in efficacy. Soil Biology and Biochemistry 34:181-188, https://doi.org/10.1016/S0038-0717(01)00165-1

Xavier L. J. C. and J. J. Germida (2003) Selective interactions between arbuscular mycorrhizal fungi and Rhizobium leguminosarum bv. viceae enhance pea yield and nutrition. Biology and Fertility of Soils 37:261-267, https://doi.org/10.1007/s00374-003-0605-6

Zhu C. X., F. B. Song and W. H. Xu (2010) Arbuscular mycorrhizae improves low temperature stress in maize via alterations in host water status and photosynthesis. Plant and Soil 331:129-137, https://doi.org/10.1007/s11104-009-0239-z 